\title{
Novos actores no trabalho em educação: os mediadores socioeducativos
}

\author{
Ana M. Costa e Silva \\ Universidade do Minho, Portugal \\ Ana Paula Caetano \& Isabel Freire \\ Universidade de Lisboa, Portugal \\ M. Alfredo Moreira \& Teresa Freire \\ Universidade do Minho, Portugal
}

Ana Sousa Ferreira

Universidade de Lisboa, Portugal

\begin{abstract}
Resumo
A mediação, enquanto prática socioeducativa, apesar de ser uma actividade com crescente visibilidade e enquadramento legal, tem ainda poucos estudos realizados que permitam a caracterização das actividades de mediação e do perfil dos mediadores socioeducativos. O estudo realizado teve dois objectivos centrais: identificar e definir o perfil socioprofissional dos mediadores socioeducativos e caracterizar contextos e práticas de mediação socioeducativa. Apesar de ser uma investigação em extensão, realizada em Portugal a nível nacional $(\mathrm{N}=225)$, é um estudo exploratório e predominantemente descritivo. A análise dos resultados obtidos no estudo realizado permite salientar alguns aspectos relevantes, que apontam para a importância da continuidade da investigação nesta área e para o investimento neste domínio de intervenção. Destacam-se as principais características sócio-demográficas e profissionais dos mediadores socioeducativos, a diversidade de contextos, de tipos de intervenção e de formação e aspectos relativos à percepção da auto-estima individual e de pertença ao grupo.
\end{abstract}

Palavras-chave

Mediação; Mediadores; Espaços socioeducativos; Identidade profissional

\section{Introdução}

A crescente valorização social do trabalho em rede e da participação dos cidadãos e das comunidades na busca de soluções para os seus problemas favorece o aparecimento de novas práticas sociais promotoras de 
coesão social. A mediação formal, tendo (re)nascido nos anos 70 , é uma delas, tendo vindo a afirmar-se em âmbitos sociais muito distintos, a partir de uma diversidade de concepções e modelos de mediação. Assim, podemos identificar uns modelos mais orientados para a co-construção e para o reconhecimento da individualidade e da autonomia de cada um, partindo das suas perspectivas para as reconceptualizar no jogo comunicacional (modelo hermenêutico), outros modelos mais orientados para a transformação social, através de uma consciência crítica - e de uma determinação no sentido da emancipação relativamente a condicionamentos sociais - e do reconhecimento e capacitação de todos e de cada um (modelo transformativo).

A mediação, enquanto prática socioprofissional, e a figura do mediador, enquanto actor interveniente no restabelecimento de laços e interacções inexistentes ou fragilizadas, ou mesmo na prevenção de conflitos potenciando uma cultura de não violência (Xáres, 2002) e de participação responsável, tem-se tornado simbólica e socialmente relevante.

As características da sociedade actual, a (re)conceptualização das práticas de mediação e a receptividade das sociedades contemporâneas a este tipo de intervenção social têm feito com que a mediação, enquanto conceptualização teórica e prática socioprofissional, venha conhecendo uma expansão crescente. Hoje em dia, a mediação é muito mais do que uma técnica alternativa de resolução de conflitos, constituindo uma modalidade de regulação social, promotora da emancipação e da coesão social. Aplicada ao campo da educação, a mediação é ainda um meio de educação para a participação das novas gerações na construção da democracia e de educação para a paz.

A noção de mediação tem vindo a ser amplamente mobilizada encontrando-se associada a uma multiplicidade de práticas. Podemos, no entanto, encontrar nelas um denominador comum: 0 serem fundamentalmente sociais e educativas. A mediação é uma actividade fundamentalmente educativa, pois o objectivo essencial é proporcionar uma sequência de aprendizagem alternativa (nomeadamente entre pessoas em conflito, explícito ou implícito) superando o estrito comportamento reactivo ou impulsivo, contribuindo para que os participantes no processo de mediação adoptem uma postura reflexiva. Neste sentido, podemos também assumir a 
mediação como uma cultura de mudança social (Munné \& Mac-Cragh, 2006; Torremorell, 2008) que promove a compreensividade entre os diferentes participantes no processo de mediação, defende a pluralidade, as diferentes versões sobre a realidade e fomenta a livre tomada de decisões e compromissos, contribuindo para a participação democrática. As práticas de mediação orientam-se, assim, no sentido da coesão social (Bonafé-Schmitt, 2009) - dimensão social - e da cidadania activa - dimensão educativa.

A mediação socioeducativa é aquela em que nos centramos no âmbito deste estudo, e incide preferencialmente nos contextos escolares, associativos e comunitários, enquanto método de resolução e gestão alternativa de conflitos, meio de regulação social e de recomposição pacífica de relações humanas. É uma prática que ocorre em contextos educativos, tanto escolares, como de educação não formal e informal, cuja acção se pode centrar em indivíduos - e no seu desenvolvimento e inserção social - ou em grupos e comunidades - com uma dimensão colectiva e de coesão social (Luison \& Velastro, 2004).

As potencialidades da mediação para facilitar a ligação entre a escola, a família e a comunidade centram-se na valorização da comunicação com vista ao (r)estabelecimento das relações e interacções inexistentes ou fragilizadas, à aceitação e assumpção das diferenças, trabalhando no sentido do desenvolvimento de competências sociocomunicacionais e sinergias mútuas.

Neste sentido, o papel do mediador é o de accionar redes de interacção e comunicação, proporcionar as pontes, as passereles, que promovam a aproximação daqueles que não conseguem ou têm dificuldade em comunicar(-se) (Freire, 2006). Tal implica, por parte do mediador socioeducativo, uma polivalência de funções, que permita a melhoria do acesso aos recursos humanos e materiais, o apoio e articulação com outros profissionais e a criação de redes comunitárias. Trata-se, assim, de um entendimento do papel social e político da mediação, pelo que extravasa largamente a dimensão técnica em que alguns a circunscrevem. Neste sentido, convivência e coesão social não podem significar colonização e homogeneização, mas participação e heterogeneização, num quadro de reposição da confiança social (Freire \& Caetano, 2008). 
Neste quadro de intervenção socioprofissional, as situações de trabalho em que os mediadores se inscrevem são, sem dúvida, contextos de (auto)reconhecimento e satisfação pessoal e profissional. Conforme salienta Divay (2009: 243), "os mediadores encontraram o seu lugar junto de diferentes trabalhadores com quem interagem e que demonstram amplamente a sua utilidade". No entanto, como sublinha esta autora, não podemos ignorar o facto de que eles se tornaram partenaires indispensáveis, entre outras razões, porque o seu campo de intervenção é bastante elástico, o que permite recorrer-se-lhes para Ihes delegar o trabalho menos agradável - 'du sale boulot' de acordo com Hughes (1996) - ou o trabalho que existe em excesso para os outros profissionais - 'boulot en trop' como o define Cadet (2005). Serão, porventura, estas razões - causas e/ou consequências - que subjazem às situações instáveis e precárias de emprego em que se encontram - em Portugal, como noutros países europeus - e até um certo isolamento, que não tem impulsionado "a força colectiva necessária que thes permita reivindicar 'um mandato para definir os comportamentos que deverão adoptar as outras pessoas face ao seu trabalho' [Hughes, 1996: 9]" (Divay, 2009: 243). Contudo, apesar da fragilidade do seu estatuto profissional, no caso do estudo que realizámos, os mediadores manifestam uma auto-imagem colectiva pública bastante positiva, como será salientado mais à frente.

Uma profissão define-se a partir de um corpo especializado de trabalhadores, que dominam determinado conhecimento (prático e/ou teórico), considerado socialmente relevante, e que se sentem identificados entre si, considerando-se parte integrante desse colectivo. No caso dos mediadores, poderemos dizer que existe um saber com raízes sociológicas e antropológicas ancestrais, reinvestido, alargado e enquadrado no pensamento contemporâneo. Mas, em nosso entender, a sua especificidade radica mais no agir, no desenvolvimento de uma praxis, ou seja, na actividade do mediador e que, para além de uma importante componente técnica, implica uma forte componente ética e reflexiva.

As técnicas e as competências mobilizadas para a mediação são comuns a outras actividades, como a terapia, por exemplo. No entanto, na mediação elas surgem enquadradas por outras finalidades, tanto educativas como sociais. 
O campo da mediação surgiu e desenvolveu-se num quadro de raízes multidisciplinares que, como dizem Highton e Álvarez (1999: 191),

enriqueceram a profissão, mas também conseguiram confundir seu sentido de identidade; e, na forma como o mediador vê a profissão, tem um papel importante o próprio conhecimento como tal, mas também há elementos que variarão dependendo de sua própria profissão de origem.

Assim se questiona muitas vezes: será que a mediação é apenas uma função, desempenhada por diversos profissionais, como os psicólogos, os sociólogos, os juízes, os assistentes sociais, os professores ou os animadores culturais? Ou será que trabalhadores com estas múltiplas formações, que trabalham em mediação, poderão constituir um novo grupo profissional - 0 dos mediadores? Será que um sociólogo que se dedica à mediação de conflitos laborais passa a ser um mediador? Será que um psicólogo que se dedica à mediação das relações interpessoais num agrupamento de escolas se identifica como mediador? Será que cada um destes profissionais se identifica mais com a sua actividade de mediador do que com a actividade de sociólogo, de assistente social ou de psicólogo? Até que ponto se identificam como fazendo parte de uma mesma profissão? Até que ponto aqueles que se consideram mediadores socioeducativos se sentem próximos dos mediadores de outras áreas? O que contribuiu ou pode contribuir para uma maior identificação?

Cada vez é mais evidente e presente, nas sociedades contemporâneas desenvolvidas, a actividade de mediação formal em contextos institucionais diversificados. Os mediadores são trabalhadores com formações muito diferenciadas; no campo mais restrito, que aqui designamos de socioeducativo, também assim acontece.

Neste artigo pretendemos caracterizar este corpo de trabalhadores sociais, discutindo, a partir dos dados recolhidos e analisados, algumas das questões que emergem deste estudo e que dizem respeito à formação, à definição de um perfil de competências e aos contextos de trabalho, procurando identificar linhas orientadoras reconceptualizadas a partir das práticas sociais dos mediadores socioeducativos, pertinentes para a sua formação especializada. 


\section{Os mediadores socioeducativos: identidade socioprofis- sional, contextos e práticas de mediação}

\section{Metodologia do Estudo}

A recolha de dados empíricos do estudo que aqui apresentamos foi realizada durante o ano de 2008 (entre Maio e Setembro), envolvendo uma equipa de investigadoras da Universidade do Minho e da Universidade de Lisboa.

O estudo centra-se nos contextos de mediação e no perfil dos mediadores socioeducativos em Portugal, sendo de natureza exploratória e predominantemente descritiva. Tem dois objectivos fundamentais: i) identificar e definir o perfil socioprofissional dos mediadores socioeducativos e ii) identificar contextos e práticas de mediação socioeducativa que permitam sinalizar e aprofundar os conhecimentos, as capacidades e competências relevantes a integrar e desenvolver na formação de mediadores.

Para o cumprimento destes objectivos recorremos a dois instrumentos: o questionário Perfil do Mediador Socioeducativo (anexo 1), construído especificamente para este estudo, e a Escala de Auto-Estima Colectiva (Luhtanen \& Crocker, 1992, versão para investigação de Freire, 2006) (anexo 2).

O questionário, composto por questões fechadas, questões abertas e uma escala tipo Likert, teve como objectivo identificar o perfil socioprofissional dos mediadores socioeducativos em cinco dimensões: i) Identificação; ii) Caracterização Socioprofissional; iii) Percurso de Formação; iv) Perfil Profissional e v) Trajectória Profissional. A escala de auto-estima colectiva teve como objectivo avaliar a identidade social dos participantes relativamente à sua pertença ao grupo social de mediadores. Adaptou-se a escala original, que avalia a pertença a grupos em geral, para a pertença a um grupo específico (os mediadores), tal como já realizado anteriormente por outros autores em relação a outros grupos sociais específicos (cf. Crocker et al. 1994). A escala é composta por um conjunto de 16 itens, avaliados numa escala tipo Likert de 7 pontos (1- Discordo totalmente; 7- Concordo totalmente) organizados em quatro subescalas (integrando 4 itens por subescala): i) Auto-estima relativa à pertença ao grupo, que avalia o julgamento individual acerca de si enquanto membro do grupo; ii) Auto-estima 
colectiva privada, que avalia os julgamentos pessoais acerca de quão bom é pertencer ao grupo em questão; iii) Auto-estima colectiva pública, que avalia as percepções pessoais acerca de como as outras pessoas avaliam o grupo de pertença em questão e iv) Importância para a identidade, que avalia a importância da pertença ao grupo social para o auto-conceito da pessoa.

Foram distribuídos 530 questionários por diversas instituições e projectos cujos responsáveis consideraram ter mediadores socioeducativos, ou seja, mediadores a desempenharem funções no domínio da mediação escolar, comunitária e/ou intercultural. Neste sentido, a distribuição dos questionários foi intencional, procurando abranger a máxima diversidade de contextos e cobrir geograficamente todo o país. Apesar de considerarmos que a amostra recolhida é bastante expressiva, reconhecemos que existem outros contextos não considerados e que são significativos neste domínio de intervenção ${ }^{1}$.

Foram devolvidos 225 questionários, pelo que a taxa de retorno se situa nos $42 \%$. Destes, apenas um número reduzido de participantes não respondeu à totalidade das questões, optando-se por não invalidar os seus questionários. Assim, todos os questionários devolvidos foram considerados, identificando-se sempre para cada um dos resultados em análise o total de respondentes em causa.

Os dados recolhidos foram tratados no programa SPSS, versão 16,0 para Windows, visando uma análise predominantemente descritiva dos resultados: frequências de resposta (dados brutos e/ou percentagens), médias e desvios padrões, consoante o tipo de medida em análise no questionário.

\section{Resultados}

\section{Perfil demográfico e profissional dos mediadores socio- educativos}

Os mediadores socioeducativos que constituíram a amostra do nosso estudo são predominantemente do sexo feminino (81,3\%) e situam-se maioritariamente no intervalo de idades entre os $22-35$ anos $(91,1 \%)$. São mais solteiras/os $(64,6 \%)$ que casadas/os ou divorciadas/os e com prevalência da zona de residência e de trabalho em Lisboa e Vale do Tejo, 
onde trabalham e residem $39,3 \%$ dos respondentes. As zonas que se seguem são, respectivamente, Entre Douro e Minho com 21,7\%, Beira Litoral com $6,9 \%$, Alentejo com 6,4\%, Beira Interior e Estremadura e Ribatejo com 4,6\%, Algarve com $3,7 \%$ e Açores com $0,4 \%$. É de salientar a proximidade entre o local de residência e de trabalho e que, para a maioria, se localizam no mesmo concelho e/ou distrito.

Da análise do perfil demográfico e profissional dos participantes no estudo, podemos ainda concluir que a grande maioria tem uma ligação recente ao trabalho que está a desenvolver actualmente, ou seja, $80 \%$ dos respondentes exerce este tipo de trabalho desde 2006, sendo que o vínculo é precário, mas com contrato de trabalho $(72,4 \%)$, embora esse contrato seja inferior a 2 anos (apenas $28,7 \%$ dos sujeitos têm um contrato com mais de 2 anos). A grande maioria dos inquiridos $(62,9 \%)$ encontra-se no $1^{\circ}$ emprego (dado consistente com a juventude da amostra). Este facto pode ter a ver com a ainda emergente prática socioprofissional da mediação e com a precariedade profissional que lhe está associada (recibos verdes, contratos de trabalho temporário e a termo, em função da durabilidade dos projectos que os integram e suportam). Na sua maioria, foram convidados ou nomeados para exercer funções de mediação $(47,6 \%)$, mas alguns foram por concurso $(24,5 \%)$ ou por candidatura $(6,9 \%)$. Este retrato confirma o panorama, tanto nacional como europeu, relativamente à situação socioprofissional e perfil não específico dos mediadores sociais, sendo a mediação nestes contextos uma prática largamente informal e da qual ainda se sabe muito pouco (Oliveira e Galego, 2005).

\section{Contextos de trabalho e práticas dos mediadores socio- educativos}

Os participantes neste estudo desenvolvem a sua actividade profissional, enquanto mediadores socioeducativos, em diferentes contextos de trabalho: instituições públicas e privadas e programas interministeriais.

Os programas com maior expressão na nossa amostra são o Programa Escolhas (39,6\% respondentes) e o Programa para Prevenção e Eliminação da Exploração do Trabalho Infantil (PETI) e, dentro dele, o Plano Integrado de Educação e Formação (PIEF, 20\% respondentes). Das 
instituições, destacamos o Instituto de Apoio à Criança (IAC, 23,1\% respondentes) e o Centro de Apoio ao Imigrante (CNAI, 13,8\% respondentes), integrado no Alto Comissariado para o Diálogo Intercultural (ACIDI). Também a Associação Consensus (2,7\% respondentes), situada no centro do país, tem uma expressiva intervenção no campo da mediação (em contexto comunitário e escolar). Tivemos ainda um respondente do Projecto SOS Professor e um que não se enquadrava em nenhum programa e/ou instituição específicos.

Os mediadores respondentes intervêm em diferentes contextos sócioorganizacionais, embora o contexto escolar seja o que tem maior representatividade, à excepção do CNAI. Este facto decorre, por um lado, das características da mediação socioeducativa e, por outro lado, dos programas e instituições que acolhem os mediadores e que legitimam a sua intervenção. No entanto, devemos salientar que tanto os mediadores do Programa Escolhas, como do IAC, intervêm noutros contextos sócio-organizacionais, nomeadamente associativos, municipais ou outros, enquanto os mediadores do CNAI evidenciam o contexto associativo como aquele em que mais incide a sua acção.

Estes dados podem ser complementados com os que apresentamos na tabela 1, e que indicam as frequências de resposta relativamente à população-alvo da intervenção dos mediadores com maior expressão nos diferentes contextos de trabalho, assim como o tipo de mediação privilegiado junto dessa população.

\begin{tabular}{|l|c|c|c|c|c|c|}
\hline $\begin{array}{c}\text { Contexto de trabalho } \\
\text { actual/ instituição } \\
\text { Tipo de Mediação }\end{array}$ & $\begin{array}{c}\text { ACIDI/ } \\
\text { CNAI }\end{array}$ & $\begin{array}{l}\text { Programa } \\
\text { Escolhas }\end{array}$ & $\begin{array}{c}\text { PETI/ } \\
\text { PIEF }\end{array}$ & IAC & $\begin{array}{c}\text { SOS } \\
\text { Professor }\end{array}$ & Consensus \\
\hline Mediação de Conflitos & 2 & 61 & 34 & 42 & 1 & 6 \\
\hline Mediação Intercultural & 16 & 51 & 14 & 15 & 0 & 4 \\
\hline Mediação Comunitária & 1 & 74 & 25 & 35 & 0 & 4 \\
\hline Outro tipo de Mediação & 8 & 19 & 5 & 12 & 0 & 1 \\
\hline $\begin{array}{l}\text { População-alvo da } \\
\text { intervenção }\end{array}$ & Imigrantes & \multicolumn{2}{|c|}{$\begin{array}{c}\text { Jovens e alunos em situação de } \\
\text { abandono escolar e respectivas } \\
\text { familias }\end{array}$} & $\begin{array}{c}\text { Comunidade } \\
\text { Escolar }\end{array}$ & $\begin{array}{c}\text { Comunidade } \\
\text { (Escolar e } \\
\text { bairro) }\end{array}$ \\
\hline
\end{tabular}

Tabela 1 - Frequências de resposta relativamente ao tipo de mediação e população-alvo da intervenção dos participantes no estudo $(\mathrm{N}=216)$ 
Assim, os mediadores do CNAl inserem as práticas da mediação predominantemente no contexto associativo e com incidência no tipo de mediação intercultural, dado que a população-alvo de excelência com quem trabalham são imigrantes. Apesar disso, alguns mediadores reconhecem que, para além da mediação intercultural, fazem também mediação de conflitos, comunitária ou outro tipo de mediação.

A população jovem e os jovens alunos são, claramente, os que mais concentram 0 alvo da intervenção dos mediadores socioeducativos, concretamente os que trabalham no âmbito do Programa Escolhas, do PETI/PIEF e do IAC. Este facto, estará, em grande medida, relacionado com o objectivo fundamental dos programas e das instituições, assim como a forte atenção e combate ao insucesso e abandono escolar, em que as políticas socioeducativas se têm vindo a concentrar ao longo desta década, particularmente a partir de 2004/2005, em consequência do mandato da Estratégia de Lisboa. É igualmente nesta estratégia que se inserem as reedições do Programa TEIP em 2006/2007 e 2008/2009, o qual contempla a integração de mediadores nas escolas/agrupamentos de escolas.

Os contextos e modos de intervenção dos mediadores dão visibilidade ao que Luison e Velastro (2004) definem como mediação socioeducativa enquanto método de resolução e gestão alternativa de conflitos, meio de regulação social e de recomposição pacífica de relações humanas. Estes autores salientam diferentes modalidades da mediação nesses contextos. São modalidades que incidem em aspectos culturais da comunicação, como é o caso da mediação (inter)cultural; na construção de modalidades alternativas de gestão das relações sociais e de socialização; na dinamização de uma cultura de participação e aquisição de instrumentos capazes de recriarem os laços sociais; ou ainda, na prevenção e gestão dos conflitos e problemas como oportunidade de melhorar as relações sociais.

Com um mandato muito específico, para conciliarem os jovens alunos com a escola, os mediadores parecem ser actores essenciais nos contextos escolares. No domínio da sua intervenção recorrem, não só a diferentes tipos de mediação, como também a diferentes tipos de intervenção que evidenciam, precisamente, e na óptica dos inquiridos, a representação da mediação não apenas enquanto técnica específica e alternativa de resolução de conflitos, mas ainda enquanto estratégia comunicacional de gestão social, tal como podemos ler na tabela 2. 
Tabela 2 - Frequências de resposta relativamente ao tipo de mediação e tipo de intervenção dos participantes no estudo ( $N=216)$

\begin{tabular}{|c|c|c|c|c|}
\hline $\begin{array}{l}\text { Tipo de mediação } \\
\text { Tipo de intervenção }\end{array}$ & $\begin{array}{l}\text { Mediação de } \\
\text { Conflitos }\end{array}$ & $\begin{array}{l}\text { Mediação } \\
\text { Intercultural }\end{array}$ & $\begin{array}{l}\text { Mediação } \\
\text { Comunitária }\end{array}$ & $\begin{array}{l}\text { Outro tipo de } \\
\text { Mediação }\end{array}$ \\
\hline $\begin{array}{l}\text { Estabelecer a ponte entre Jovens- } \\
\text { Escola-Família }\end{array}$ & 26 & 12 & 25 & 6 \\
\hline Informação/orientação & 2 & 12 & 1 & 3 \\
\hline $\begin{array}{l}\text { Acompanhamento emocional, } \\
\text { psicológico e na resolução de conflitos } \\
\text { e problemas }\end{array}$ & 23 & 15 & 20 & 7 \\
\hline $\begin{array}{l}\text { Socioeducativa, familiar, profissional e } \\
\text { social }\end{array}$ & 50 & 30 & 49 & 22 \\
\hline Diagnóstico e Intervenção & 9 & 5 & 5 & 4 \\
\hline
\end{tabular}

A intervenção dos mediadores socioeducativos distribui-se por um continuum relacional e comunicacional. Neste contexto de interacção, o diagnóstico, a informação e a orientação são modalidades de intervenção menos expressivas do que o acompanhamento - emocional e psicológico e na resolução de conflitos ou problemas -, a intervenção socioeducativa, familiar, social e profissional e a promoção de pontes e elos de intercompreensão entre os jovens, a escola e a família.

Apesar da mediação de conflitos ter bastante expressão, particularmente no contexto escolar, a mediação comunitária e intercultural parecem ser igualmente mobilizadas no âmbito da intervenção sociopedagógica dos mediadores, conforme sistematizamos na tabela 3.

\begin{tabular}{|c|c|c|c|c|}
\hline $\begin{array}{l}\text { Contexto institucional/social } \\
\text { de mediação }\end{array}$ & $\begin{array}{l}\text { Contexto } \\
\text { Escolar }\end{array}$ & $\begin{array}{l}\text { Contexto } \\
\text { Associativo }\end{array}$ & $\begin{array}{l}\text { Contexto } \\
\text { Municipal }\end{array}$ & $\begin{array}{c}\text { Outro } \\
\text { Contexto }\end{array}$ \\
\hline Mediação de Conflitos & 120 & 34 & 21 & 24 \\
\hline Mediação Intercultural & 67 & 35 & 13 & 16 \\
\hline Mediação Comunitária & 106 & 46 & 26 & 25 \\
\hline Outro tipo de Mediação & 32 & 17 & 3 & 10 \\
\hline
\end{tabular}

Tabela 3 - Frequências de resposta relativamente ao contexto de mediação e tipo de mediação ( $\mathrm{N}=216)$

Neste sentido, os mediadores recorrem a abordagens e estratégias educacionais que, mesmo quando situadas em contextos escolares, 
procuram desenvolver dinâmicas comunicacionais de compreensão e intercompreensão, de pontes e (re)conciliações que as pedagogias estritamente escolares parecem não conseguir, ou simplesmente não definir como prioritárias na sua acção.

Esta diversidade de intervenções é assumida pelos diferentes mediadores, independentemente das funções que desempenham - de coordenadores da equipa, mediadores especializados ou outro - como se pode ver na tabela 4 .

\begin{tabular}{|l|c|c|c|}
\hline \multicolumn{1}{|c|}{ Função que desempenha } & Coordenação & $\begin{array}{c}\text { Mediador/a } \\
\text { especializado/a }\end{array}$ & Outro \\
\hline Esipo de intervenção & 11 & 6 & 17 \\
\hline Informação/orientação & 3 & 11 & 1 \\
\hline Mediação de conflitos & 2 & 5 & 6 \\
\hline $\begin{array}{l}\text { Acompanhamento emocional, psicológico e } \\
\text { resolução de conflitos e problemas }\end{array}$ & 6 & 11 & 14 \\
\hline Socioeducativa, familiar, profissional e social & 19 & 23 & 25 \\
\hline Animação Sociocultural & 2 & 4 & 7 \\
\hline Diagnóstico e Intervenção & 2 & 3 & 5 \\
\hline
\end{tabular}

Tabela 4 - Frequências de resposta relativamente à função desempenhada e ao tipo de intervenção $(\mathrm{N}=216)$

É igualmente relevante salientar que, independentemente dos contextos em que ocorre a mediação, a modalidade de intervenção em equipa é aquela que mais é mobilizada pelos mediadores.

O facto de intervirem fundamentalmente em equipa, embora nalguns casos também individualmente, parece evidenciar a mobilização de distintos recursos humanos. Intervêm, com frequência, distintos profissionais e instituições diversas, já que a intervenção em equipa multidisciplinar em rede é igualmente identificada com uma razoável incidência.

Esta característica é mais um indicador de que a sua intervenção mobiliza outros recursos, para além da simples técnica de resolução alternativa de conflitos - esta última preferencialmente implementada individualmente por mediadores especializados. Traduz a natureza multidisciplinar e multifuncional da mediação socioeducativa, que se assume 
como actividade complexa, mobilizadora de diferentes perfis e competências pessoais e profissionais.

Relativamente às razões que movem este grupo de mediadores para trabalharem no âmbito da mediação socioeducativa, estas dividem-se entre as de ordem institucional (42,1\%) e/ou pessoal/ profissional (48,1\%): as primeiras agrupam motivos tais como entender a mediação como instrumento organizacional essencial, decorrentes do cargo e função que desempenham, do contexto de aç̧ão (escola ou outros), de uma necessidade institucional e filosofia do projecto. De referir, ainda, que estas razões de ordem institucional surgem relacionadas com modalidades de intervenção junto de jovens, alunos e famílias, de natureza socioeducativa e de resolução de conflitos. As segundas, de ordem pessoal/profissional, agrupam motivos tais como estar a desenvolver formação, ter interesse pela área, partilhar valores pessoais e profissionais condicentes com a prática da mediação, ou ainda encarar a mediação como uma nova experiência e oportunidade de aprendizagem, merecedora de promoção e divulgação. As funções de coordenação $(22,6 \%)$ surgem relacionadas com uma combinação de ambas as ordens de razão interesse pela mediação e necessidades institucionais/filosofia do projecto, ou ainda pela natureza do cargo desempenhado.

Podemos, assim, perceber razões associadas ao reconhecimento das potencialidades da mediação tanto do ponto de vista mais instrumental, como do ponto de vista filosófico e ético. Noutros casos, embora em muito menor número, são razões circunstanciais, nomeadamente de último recurso no acesso ao emprego. Todavia, e apesar da diversidade de motivos que levam estes sujeitos a exercerem funções de mediação socioeducativa, a grande maioria dos inquiridos $(77,3 \%)$ manifesta interesse em continuar a exercer funções na área da mediação pelos seguintes motivos: identificação com a área (24\%); constituir uma gratificação pessoal e profissional $(14,3 \%)$; ser uma área aliciante, desafiadora e motivadora $(12,5 \%)$ e ser uma prática importante para o bem comum (12\%).

Estas razões, apresentadas como as mais significativas e representativas, apontam para um forte compromisso social dos respondentes, que estará na base do sentimento de gratificação pessoal e profissional. Esta gratificação e (auto)reconhecimento parece ser mais de ordem moral (julgamento de utilidade: do que fazem e quanto fazem; e de 
beleza: como fazem), do que material (expresso em espécie: vencimento ou promoção) (Déjours, 1993). A forte identificação com a sua área de trabalho, associada à percepção de um trabalho em prol de um bem colectivo, parece ser a motivação maior destes sujeitos para a prática da mediação, não obstante a precariedade laboral, a fragilidade do vínculo profissional, ou a falta de reconhecimento material no trabalho que realizam, como coloca Déjours (1993).

Contudo, estes mediadores vêem-se a cumprir uma função social relevante, de recomposição pacífica de relações humanas (Luison e Valastro, 2004) e configuradora de uma cultura de mudança social (Torremorell, 2008), que actua em prol de níveis elevados de satisfação pessoal e profissional.

Assim, as suas expectativas para o futuro são, claramente, continuar a exercer a sua actividade profissional nesta área ou em área afim, conforme referem $41,2 \%$ dos respondentes. Todavia, um número significativo $(9,7 \%)$ indica não ter expectativas profissionais, possivelmente por reconhecer a provisionalidade da função e a sua instabilidade profissional.

\section{Percurso de formação e expectativas}

Os mediadores socioeducativos que participaram neste estudo têm na sua maioria uma formação académica de nível superior $(92,1 \%)$, sendo que $25,3 \%$ possuem habilitações ao nível da pós-graduação, como mestrado e doutoramento ( $8,4 \%$ dos mediadores). Trata-se, portanto, de uma população que tendo, é certo, bastante heterogeneidade ao nível das habilitações académicas (do $9^{\circ}$ ano ao doutoramento), é maioritariamente de qualificação superior.

A formação dos mediadores que possuem habilitações académicas e profissionalizantes de nível médio ou superior é bastante diversificada, salientando-se a formação em Psicologia (37,6\%), em Educação (20,5\%) e em Serviço Social (18,9\%). Também as especializações em cada uma destas áreas são múltiplas, havendo mediadores licenciados em Psicologia Social, Clínica, Criminal, da Justiça e da Reinserção Social, no caso da Psicologia. $\mathrm{Na}$ área da Educação, verificam-se também especializações variadas, como as licenciaturas em Ensino, Ciências da Educação, Educação Social ou Educação Física e Desporto.

As habilitações de pós-graduação são igualmente muito diversificadas, sendo as mais frequentes, mais uma vez, em Psicologia, e também em 
Gestão de Diversidade e Comunidades de Prática. Com formação em mediação de conflitos surgem dois mediadores.

No que respeita ao nível académico de mestrado, mais uma vez o destaque vai para a formação em Psicologia (12 dos 18 mediadores com mestrado).

A preparação para o exercício da função destes mediadores apresenta-se, assim, muito diversa, tendo como áreas nucleares aquelas que preparam para a intervenção psico-sócio-educativa. Contudo, também se verifica a presença de mediadores com outros tipos de formação, como Ciência Política, Estudos Europeus, Geografia e Planeamento, para dar alguns exemplos. Uma das explicações para esta realidade será a carência de trabalho no nosso país para os jovens qualificados com formação superior, mas naturalmente que o conceito aberto de mediador e a falta de definição de um perfil quer de formação, quer de desempenho também ajudam a explicar esta multiplicidade de formações.

Por outro lado, em relação à formação profissionalizante para o exercício da mediação, apenas $15 \%$ dos respondentes afirmam terem-na adquirido, sendo as mais frequentes nas áreas de Mediação (18 respondentes), Animação Sociocultural (6 respondentes) e Gestão de Recursos Humanos (4 respondentes).

A formação específica em mediação surge como predominante, seguida da animação sociocultural. Dos respondentes com habilitações profissionalizantes, oito afirmam ter realizado estágio e cinco não o ter feito.

Estas formações são relativamente recentes, na medida em que $6 \%$ dos respondentes mencionam terem-nas realizado entre 2001 e 2005, e outros $6 \%$ de 2006 a 2008, o que revela que, de facto, a formação nesta área começa agora a dar os seus primeiros passos.

Há, ainda, outras formações consideradas relevantes para $32 \%$ dos respondentes, com destaque para a formação de formadores (14 respostas), e formação relacionada com a imigração (8 respostas). De realçar ainda a referência a formação em terapia familiar e parentalidade feita por 5 mediadores inquiridos.

Questionados acerca das suas perspectivas sobre a formação futura, verifica-se que a maioria dos mediadores prefere uma formação especializada (72,4\%), nomeadamente na área da mediação $(26,6 \%)$, embora também alguns se pronunciem a favor de uma formação pós-graduada $(20 \%)$ e outros por cursos de curta duração $(26,6 \%)$. Para 4 dos mediadores, constitui perspectiva preferencial de formação, a conclusão da formação académica básica. Sem 
apontarem preferências; 9\% dos respondentes referem ter expectativas de realizar formação ao nível de mestrado (6,6\%) e de doutoramento (3\%); 4 respondentes perspectivam investir noutra área de formação.

No que respeita às áreas de actuação onde gostariam de receber formação, há uma grande diversidade de respostas, embora se destaquem as relativas à mediação de conflitos, familiar e educativa $(41,7 \%)$, à interculturalidade $(4 \%)$, às problemáticas de risco $(5,7 \%)$, às relações interpessoais (3,5\%) e à animação socioeducativa (2,2\%).

Numa tentativa de compreensão da relação entre as expectativas de formação e os contextos de trabalho, os dados apontam para a preferência por formação especializada em mediação para o conjunto dos respondentes (34\%). Contudo, e apesar de as diferenças não serem estatisticamente significativas, observa-se uma tendência para essa preferência ser mais forte no caso dos mediadores do CNAI, do IAC e do PIEF, enquanto que os do Programa Escolhas tendem a preferir uma formação especializada de curta duração.

Estes resultados parecem apontar para necessidades e interesses no quadro da formação específica em mediação, dimensão central na intervenção deste conjunto de trabalhadores que, neste aspecto, parecem estar bastante sintonizados, apesar da variedade de contextos de acção. Este colectivo de mediadores desempenha, como vimos, funções bastante diversificadas, decorrentes das exigências do contexto de trabalho e do enquadramento institucional do mesmo, mas também dependendo da própria interpretação que cada mediador faz do seu papel e das suas funções, muitas vezes associada à sua formação de base. Parece existir uma consciência alargada a um grande grupo de respondentes de que necessitam e desejam formação para o desenvolvimento das suas competências para a mediação.

É de salientar a frequência relevante de respondentes que deseja realizar formação pós-graduada especializada (27\%). Toda a informação relativa à formação realizada e desejada denota que este conjunto de mediadores, não obstante a sua elevada qualificação académica, apresenta uma predisposição para a formação no sentido de uma especialização.

\section{Competências, saberes e cuidados do mediador}

No questionário que serviu de base a este estudo, pretendemos ainda captar a valorização que os respondentes fazem de um conjunto de aspectos ligados ao desempenho dos mediadores. Para tal, apresentou-se um conjunto de itens, de resposta tipo likert (escala de 4 pontos, para além da resposta 
"sem opinião"), construídos a partir da revisão da literatura e também a partir da análise de entrevistas exploratórias a mediadores realizadas em estudos prévios (Freire e Caetano, 2008; Caetano e Freire, 2006). Na tabela 5, apresentamos os resultados obtidos, por item, considerando os pontos da escala (de importância).

Como se pode verificar, dos 36 itens, a maior parte (20) apresentam a moda no ponto cinco da escala (muito importante). Destes 20 itens, oito estão claramente associados aos processos de comunicação interpessoal (estar disponível para os outros; ser capaz de ouvir os outros; ser flexível; ser assertivo; ser empático na relação com os outros; ser imparcial; promover o diálogo entre pessoas ou grupos; ser capaz de gerir a comunicação interpessoal), que referenciam o mediador a alguém que ajuda os outros a encontrar formas de comunicação que conduzam a patamares mais elevados de auto e de hetero-conhecimento. Para tal, o mediador tem de ser alguém que domina técnicas de comunicação, como a escuta activa, a assertividade, a empatia, a imparcialidade, a gestão da dinâmica de grupos, etc. Um outro núcleo de itens, também considerados muito importantes pela maior parte dos respondentes, pode ser associado à capacidade de observar e analisar os contextos, para uma aç̧ão adequada (ser bom observador/estar atento ao que o rodeia; ser capaz de identificar problemas; conhecer traços culturais dominantes da população com quem trabalha; conhecer os códigos linguísticos da população). Surge um outro conjunto de itens, igualmente valorizados pela maioria como muito importantes, conotado com qualidades pessoais dos mediadores, como a responsabilidade, o autocontrolo, a motivação, a paciência, a resistência às adversidades e a capacidade de inspirar respeito junto dos outros. Finalmente, dois itens, cuja moda se situa no ponto cinco da escala, valorizam a dimensão ética do trabalho do mediador, ao sublinharem o valor do respeito pelo outro e o do interesse pelo bem comum. Registe-se que na lista dos 36, o item "respeitar o outro" é um dos que acolhe mais respostas no nível cinco da escala (168). Num nível mais elevado da escala apenas se situam dois itens: "ser capaz de ouvir os outros" (183) e "estar motivado para aquilo que faz" (170). Digamos que, para estes mediadores, o que mais é valorizado nas qualidades do mediador é o saber ouvir, a motivação para a acção e o ser capaz de respeitar o outro, onde se cruzam a dimensão comunicacional, a dimensão volitiva e a dimensão ética, parecendo constituir estas três dimensões, o "coração" da mediação. 


\begin{tabular}{|c|c|c|c|c|c|}
\hline $\begin{array}{l}\text { Aspectos ligados ao desempenho } \\
\text { do mediador }\end{array}$ & $\begin{array}{l}\text { Sem } \\
\text { opinião }\end{array}$ & $\begin{array}{c}\text { Nada } \\
\text { importante }\end{array}$ & $\begin{array}{c}\text { Pouco } \\
\text { importante }\end{array}$ & Importante & $\begin{array}{c}\text { Muito } \\
\text { importante }\end{array}$ \\
\hline $\begin{array}{l}\text { Conhecer os códigos linguísticos da } \\
\text { população }\end{array}$ & 4 & 2 & 11 & 87 & 109 \\
\hline Estar disponível para os outros & 1 & - & 2 & 53 & 158 \\
\hline Ser corajoso & 7 & 15 & 54 & 97 & 39 \\
\hline Ser responsável & 2 & 1 & 2 & 58 & 150 \\
\hline Ser flexivel & 1 & 3 & 6 & 85 & 117 \\
\hline Ser capaz de ouvir os outros & 1 & - & - & 29 & 183 \\
\hline Ser prudente & 3 & 3 & 21 & 107 & 79 \\
\hline Ser capaz de identificar problemas & 1 & - & 4 & 64 & 142 \\
\hline $\begin{array}{l}\text { Conhecer traços culturais dominantes da } \\
\text { população com quem trabalha }\end{array}$ & 2 & 2 & 10 & 91 & 106 \\
\hline Ser assertivo & 2 & 3 & 3 & 8 & 125 \\
\hline Ser auto-confiante & 4 & 1 & 16 & 102 & 90 \\
\hline Ser empático na relação com os outros & 3 & - & 9 & 69 & 133 \\
\hline Ter sentido de humor & 6 & 6 & 48 & 110 & 41 \\
\hline Ser imparcial & 4 & 2 & 16 & 81 & 107 \\
\hline Acreditar no outro & 3 & 10 & 27 & 115 & 88 \\
\hline $\begin{array}{l}\text { Promover o diálogo entre pessoas ou } \\
\text { grupos }\end{array}$ & 1 & - & 5 & 69 & 137 \\
\hline Ter autocontrolo & 3 & 1 & 6 & 81 & 122 \\
\hline Respeitar o outro & 1 & - & 1 & 44 & 168 \\
\hline Ser paciente & 1 & 1 & 11 & 100 & 101 \\
\hline $\begin{array}{l}\text { Ser capaz de gerir a comunicação } \\
\text { interpessoal }\end{array}$ & 1 & - & 4 & 63 & 146 \\
\hline Ser tolerante ao stress & 3 & 1 & 10 & 116 & 84 \\
\hline Ser criativo & 3 & 2 & 16 & 110 & 82 \\
\hline Ser realista & 4 & 3 & 12 & 118 & 77 \\
\hline Ser resistente às adversidades & 3 & 1 & 8 & 98 & 103 \\
\hline Ser optimista & 4 & 1 & 21 & 112 & 75 \\
\hline Interessar-se pelo bem dos outros & 2 & 1 & 18 & 78 & 115 \\
\hline Ser perseverante & 4 & 1 & 8 & 113 & 86 \\
\hline Ser respeitado na comunidade/grupo & 1 & 3 & 11 & 72 & 122 \\
\hline $\begin{array}{l}\text { Tentar resolver os problemas o mais } \\
\text { depressa possível }\end{array}$ & 4 & 8 & 54 & 100 & 44 \\
\hline $\begin{array}{l}\text { Ser capaz de gerir a agressividade dos } \\
\text { outros }\end{array}$ & 2 & - & 5 & 108 & 96 \\
\hline Ser simpático & 2 & 6 & 32 & 115 & 57 \\
\hline Ser falador & 9 & 25 & 99 & 62 & 15 \\
\hline Saber resolver os conflitos dos outros & 8 & 10 & 33 & 91 & 67 \\
\hline $\begin{array}{l}\text { Ser bom observador/estar atento ao que o } \\
\text { rodeia }\end{array}$ & 8 & - & 4 & 66 & 142 \\
\hline Estar motivado para aquilo que faz & 1 & - & 1 & 12 & 170 \\
\hline Ser muito activo & 2 & 3 & 20 & 115 & 74 \\
\hline
\end{tabular}

Tabela 5 - Frequências de resposta por item relativamente a aspectos ligados ao desempenho dos mediadores $(\mathrm{N}=\mathbf{2 1 6})$ 
A análise destes dados indicia, contudo, que neste colectivo de mediadores estudado, também se revela, para muitos, uma interpretação do papel do mediador ligada a um desempenho mais imediatista e pragmático, o que se pode inferir a partir do peso que tem a soma das frequências das respostas no nível 4 (importante) e 5 (muito importante) nos itens: tentar resolver os problemas o mais depressa possível (144); saber resolver os conflitos dos outros (158); ser muito activo (189).

\section{Auto-estima colectiva do mediador}

A escala utilizada para medir a auto-estima colectiva dos participantes permite um conjunto de análises acerca da sua identidade social, em relação à sua pertença a grupos sociais. Para efeitos deste estudo, apenas se considerou uma análise descritiva no sentido de caracterizar o grupo de respondentes, em termos das quatro dimensões que compõem a escala, relativamente à sua pertença ao grupo de profissionais da mediação. Para tal, analisaram-se os valores médios de cada uma das subescalas. Nesta versão adaptada ao grupo de mediadores, as subescalas que apresentam valores de consistência interna - alpha de Cronbach - aceitáveis (Almeida \& Freire, 2009) são as relativas à auto-estima privada e pública (respectivamente 0.71 e 0.77), tal como definidas anteriormente neste artigo. Quanto às outras duas subescalas, os valores obtidos foram de 0.57 para a escala relativa à pertença ao grupo e de 0,58 para a subescala relativa à importância da pertença ao grupo para o auto-conceito, pelo que apenas são apresentados os dados relativos às escalas de auto-estima colectiva privada e pública.

Atendendo aos valores médios obtidos por sub-escala, os resultados mostram que os participantes deste estudo apresentam julgamentos pessoais positivos ( $N=214, M=5.91, S D=.93)$ no sentido da sua pertença ao grupo em questão (auto-estima colectiva privada), bem como consideram igualmente positivos $(\mathrm{N}=219, \mathrm{M}=5.93, \mathrm{SD}=.85)$ os julgamentos que os outros fazem acerca do seu grupo de pertença (auto-estima colectiva pública). Ou seja, podemos concluir acerca da positividade associada à auto-estima colectiva destes participantes, quer pública, quer privada, sendo no entanto de realçar que não podemos tecer considerações acerca dos julgamentos e percepções relativos à sua pertença como membros do grupo social de mediadores, nem a influência dessa pertença em termos do seu auto-conceito 
pessoal. No entanto, os resultados obtidos são sem dúvida, importantes, sobretudo quando está em causa a análise da emergência e consequente identificação social de um determinado grupo profissional, como é o caso dos mediadores. Tal processo de análise implica necessariamente considerações acerca dos aspectos que são comuns e, simultaneamente, diferenciadores entre o grupo de mediadores e outros grupos profissionais, tentando compreendê-los à luz dos processos sociais de categorização, individuais e colectivos, que estão na base da representação de grupos sociais, nomeadamente dos grupos profissionais, num determinado contexto societal.

\section{Conclusões}

A análise dos resultados obtidos no estudo realizado permite salientar alguns aspectos relevantes, que apontam para a importância da continuidade da investigação nesta área a fim de melhor ser cartografado um território ainda largamente desconhecido, bem como para o investimento neste domínio de intervenção.

Neste sentido, salientam-se as principais conclusões relativamente ao perfil, demográfico e profissional dos mediadores socioeducativos. Pode afirmar-se que os mediadores que participaram neste estudo são sobretudo mulheres, solteiras, jovens, a viver e a trabalhar na área de Lisboa e Vale do Tejo, a exercer a actividade de mediação por motivações variadas, que abarcam as de ordem pessoal, profissional ou institucional, embora na sua grande maioria sem vínculo laboral estável. Revelam níveis elevados de satisfação pessoal e profissional com o exercício destas funções e trabalham em contextos e com populações muito diversificados.

Relativamente à sua formação, apresentam habilitações académicas bastante heterogéneas, com predomínio das habilitações de nível superior e com uma incidência relevante de mediadores com cursos de pós-graduação. Observa-se, não obstante, uma carência de formação especializada, designadamente no domínio específico da mediação.

O grupo estudado encontra-se a trabalhar sobretudo no âmbito de projectos e programas de mediação dirigidos a populações jovens e no âmbito escolar, dando forte atenção e combate ao insucesso e abandono escolar (Programa Escolhas, Programa para a Prevenção e Eliminação da 
Exploração do Trabalho Infantil e Instituto de Apoio à Criança). Estes mediadores desenvolvem o seu trabalho em equipa, percepcionando-se a efectuar mediação de conflitos, intercultural e comunitária, com uma intervenção de natureza variada: socioeducativa, familiar, profissional e social. Aliás, a diversidade caracteriza a amostra de mediadores deste estudo: desde a diversidade de percursos académicos e formações, à diversidade de contextos, de tipo de intervenção, e da população junto de quem intervêm. Apesar desta diversidade (e talvez exactamente pela sua presença) e da precariedade do exercício da função de mediador, este grupo identifica-se fortemente com a mesma, revelando ter interesse pessoal e profissional no desenvolvimento de competências e na aquisição de formação especializada, bem como na continuidade do trabalho. A explicar os níveis elevados de satisfação com a função, estes mediadores vêem-se a cumprir uma função social relevante, de transformação dos contextos sociais e educativos, colocando-se ao serviço de um bem social que transcende lógicas e interesses individuais e institucionais. Os contextos e modos de intervenção revelam que a mediação socioeducativa é assumida, nas práticas dos mediadores respondentes, enquanto método de resolução e gestão alternativa de conflitos, meio de regulação social e de recomposição pacífica de relações humanas (Luison e Velastro, 2004) e configuradora de uma cultura de mudança social (Torremorell, 2008).

Quanto às competências, saberes e cuidados a ter na mediação, a leitura dos dados indica uma interpretação dominante do papel do mediador, orientado para a facilitação dos processos de comunicação junto das pessoas ou grupos com que trabalha, a partir de uma observação e análise dos contextos e orientado por e para uma dimensão ética. Porém, também se denota alguma valorização de modos de agir e de interpretar o papel do mediador numa linha mais imediatista e pragmática.

De salientar os valores pouco significativos relativos às subescalas de pertença ao grupo e à importância da pertença ao grupo para o auto-conceito, que podem estar associados ao facto de a grande maioria dos respondentes ter uma formação de base específica, podendo essa ser dominante na sua identificação ao grupo profissional de pertença, secundarizando o seu sentido de pertença ao grupo dos mediadores. Este resultado vem corroborar o panorama de alguma indefinição das fronteiras da actividade e da sua clara delimitação relativamente a outras actividades que com ela se confundem e 
sobrepõem, dado que também tomam os valores da comunicação, emancipação, coesão e integração social como cruciais à sua função.

Os aspectos da identidade social, relacionados com a auto-estima e auto-conceitos colectivos, emergem como relevantes e fundamentais neste estudo, revelando os respondentes julgamentos pessoais positivos acerca do grupo social de mediadores a que pertencem, bem como acerca dos julgamentos que os outros fazem do seu grupo. Todavia, salienta-se a necessidade de continuar a exploração destes dados para uma crescente compreensão dos aspectos individuais, sociais e estruturais associados a estes novos actores no trabalho em educação.

O número elevado de mediadores que se manifesta satisfeito com a actividade de mediação e a sua receptividade em continuar a intervir nesta área, associado à reduzida formação especializada na área da mediação que têm, são elementos a ter em consideração para o investimento e oferta de formação especializada pelas instituições de formação, nomeadamente de nível superior, mas também ao longo da vida, de natureza profissionalizante e em contexto de trabalho.

Há necessidade de um efectivo investimento, não só na criação de condições de continuidade laboral para este conjunto de trabalhadores, como na sua formação abrangente e especializada, multidisciplinar e contextualizada, nomeadamente em áreas de desenvolvimento de competências de comunicação, conhecimento intrapessoal e relacionamento interpessoal. Apontamos ainda o desenvolvimento de capacidades de resolução de problemas e de conflitos, e o aprofundamento de saberes relacionados com o conhecimento dos contextos em que os mediadores actuam, no quadro de uma formação de natureza profissionalizante ou especializada. Neste sentido, a formação no domínio específico da mediação deve ter, igualmente, em atenção a contextualização da intervenção dos mediadores socioeducativos que, de acordo com os resultados deste estudo, se integram em contextos institucionais, programas e áreas diversas de intervenção. Estes dados parecem apontar, pois, para a necessidade de um maior fortalecimento do corpo de saberes considerado básico para o exercício da mediação, não só técnicos mas também éticos e sistémicos, mas também se faz pela multiplicação e diversificação de níveis e de áreas de formação, num contexto de desenvolvimento profissional ao longo da vida, alicerce para 
a construção de uma identidade profissional que se fortalece na complexidade e diversidade de contextos e trajectórias (Caetano, 2009).

Só um efectivo investimento na formação destes agentes educativos reconhecerá, social e legalmente, a natureza multidisciplinar e complexa da mediação, que se assume como conceito aberto e actividade mobilizadora de diferentes perfis e competências pessoais e profissionais, mas onde podemos destacar o papel da qualificação e da formação, bem como critérios ajustados às exigências dos contextos no seu recrutamento e selecção (cf. Oliveira e Galego, 2005). Em nosso entender, a falta de definição de um perfil especializado, quer de formação quer de desempenho, não favorecem o reconhecimento social e legal de uma actividade cada vez mais fundamental na educação para uma cidadania responsável e pacífica nas sociedades contemporâneas.

O desafio pode situar-se, precisamente, em encontrar respostas onde unidade e diversidade se conciliem. Tal pode passar pela definição de um perfil abrangente, que reconheça um núcleo comum de funções, competências e saberes, ao mesmo tempo que abre e inclui a necessidade da diversidade, decorrente da multiplicidade de contextos e tipos de intervenção requeridos. A procura de respostas a estas e outras questões requer a continuação de uma abordagem investigativa que envolva os próprios mediadores, nomeadamente em processos de investigação-acção, o que poderá constituir uma via com muitas potencialidades transformadoras.

\section{Nota}

1 Não integram esta amostra os mediadores que se encontravam a trabalhar em escolas TEIP (Territórios Educativos de Intervenção Prioritária), sabendo a equipa que a nível nacional existiam 21 mediadores neste âmbito nos 35 Agrupamentos de Escolas abrangidos, tendo já sido iniciada a recolha de dados junto destes mediadores. Não foram ainda integrados os mediadores pessoais e sociais que trabalham no âmbito da Educação e Formação de Adultos (habitualmente denominados como Mediadores EFA). Não tendo sido contemplados na fase do estudo a que nos reportamos, consideramos ser essencial inclui-los numa fase posterior, pela representatividade crescente em contextos específicos no domínio da mediação socioeducativa. 


\section{Referências}

ALMEIDA, Leandro \& FREIRE, Teresa (2009). Metodologia da Investigação em Psicologia e Educação: 5a Edição, Braga: Psiquilibrios.

BONAFÉ-SCHMITT, Jean-Pierre (2009). Mediação, Conciliação, Arbitragem: Técnicas, ou um novo modelo de regulação social. In A. M. Silva \& M. A. Moreira (Orgs), Formação e Mediação Sócio-Educativa: Perspectivas Teóricas e Práticas. Porto: Areal Editores.

CADET, Jean-Pierre (2005). Emploi-jeune de l'Éducation Nationale. Une condition d'emploi riche d'enseignements. Travail et Emploi, oㅡ 101, janviers-mars, pp. 2129.

CAETANO, Ana Paula (2009). Questões de legitimidade e poder na mediação sócioeducativa. In A. M. Silva \& M. A. Moreira (Orgs), Actas do Seminário Mediação Socioeducativa: Contextos e Práticas, Braga, 12 de Dezembro, CD Rom.

CAETANO, Ana Paula \& FREIRE, Isabel (2006). La Médiation Scolaire comme Stratégie d'Intervention Auprès des Jeunes à Risque. European Conference on Educational Research. ECER Genève, 2006, European Conference on Educational Research Journal [Em linha] [disponível em http://www.leeds.ac.uk/educol/documents/158725.htm]

CROCKER, Jennifer; LUHTANEN, Riia; BLAINE, Bruce \& BROADNAX, Stephanie (1994). Collective self-esteem and psychological well-being among White, Black, and Asian College students. Personality \& Social Psychology Bulletin, 20(5), pp. 503-513.

DEJOURS, Christophe (1993). Intelligence pratique et sagesse pratique: deux dimensions méconnues du travail réel. Education Permanente, № 116, pp. 4770 .

DIVAY, Sophie (2009). La médiation sociale: « un nouveau métier » plus de dix ans après son émergence? In D. Demazière \& Ch. Gadéa (dir.), Sociologie des Groupes Professionnels. Acquis Récents et Nouveaux Défis. Paris: La Découverte, pp. 242-251.

FREIRE, Isabel \& CAETANO, Ana Paula (2008). Mediação sócio-educativa - a emergência de um novo perfil profissional. Revista Arquipélago - Ciências da Educação, 9, pp. 169-194.

FREIRE, Isabel (2006) Mediação em educação em Portugal - contextos e práticas. In Actas do XV Colóquio Nacional da AIPELF/AFIRSE, Lisboa, Fevereiro de 2005, Lisboa: Faculdade de Psicologia e de Ciências da Educação, Universidade de Lisboa.

FREIRE, Isabel (2009). Mediação e formação: em busca de novas profissionalidades e de novos perfis profissionais. In A. M. Costa e Silva \& M. A. Moreira (Orgs.), Formação e Mediação Sócio-educativa, Porto: Areal Editores, pp. 41-46.

HIGTON, Elena Inés \& ÁLVAREZ, Gladys Stella (1999). A mediação no cenário jurídico: seus Limites - a tentação de exercer o poder e o poder do mediador segundo a sua profissão de origem. In D. F. Schnitman \& S. Littlejohn (orgs), Novos Paradigmas em Mediação, Porto Alegre: Artmed Editora, pp.185-206.

HUGHES, Everet (1996). Le regard sociologique. Essais choisis. Textes choisis par J.M. Chapoulie. Paris: Editions de L'EHESS. 
JARES, Xesús (2002). Educação e Conflito. Guia da Educação para a Convivência. Porto: Edições ASA.

MUNNÉ, Maria \& MAC-CRAGH, Pilar (2006). Los 10 princípios de la Cultura de Mediación. Barcelona: Graó.

LUHTANEN, Riia \& CROCKER, Jennifer (1992). A collective self-esteem scale: selfevaluation of one's social identity. Personality and Social Psychology Bulletin, 18, pp. 302-318.

LUISON, Lucio \& VELASTRO, Orazio Maria (2004). Du processus aux pratiques de médiation. Esprit Critique, Êté 2004, Vol. 6, № 03. [Em linha] [Acedido em 28/Abril/2008, disponível em http://www.espritcritique.org]

OLIVEIRA, Ana \& GALEGO, Carla (com a colaboração de Laura Godinho) (2005). A Mediação Sócio-cultural: um Puzzle em Construção. Lisboa: ACIME.

TORREMORELL, Maria Carme Boqué (2008). Cultura de Mediação e Mudança Social. Porto: Porto Editora. 


\section{NEW ACTORS IN EDUCATIONAL WORK: SOCIAL AND EDUCATIONAL MEDIATORS}

Abstract

Although it is not a new social and educational practice, studies on characterization of mediation activities and on the profile of social and educational mediators are still scarce. In this paper the research team had two main purposes: to identify and to define the profile of social and educational mediators, and to characterize contexts and practices of social and educational mediation. Even though it is an extensive study, undertaken nationwide in Portugal ( $\mathrm{N}=225)$, this is still an exploratory study, mainly descriptive. Result analysis makes it possible to identify relevant aspects for coming research in this area along with avenues for future investment. The main professional and social and demographic characteristics of social and educational mediators stand out, as well as the diversity of contexts, the nature of their intervention, the diversity of education and training, and high individual self-esteem and sense of belonging to the group by the participants.

Keywords

Mediation; Mediators; Social and educational practices; Professional identity 


\title{
DE NOUVEAUX ACTEURS À L'CEUVRE DANS L'ÉDUCATION: LES MÉDIATEURS SOCIO-ÉDUCATIFS
}

\author{
Résumé
}

Quoique la médiation socio-éducative se constitue, dès lors, comme une activité à visibilité croissante et possède un encadrement légal, les études qui permettent la caractérisation des activités de médiation et du profil des médiateurs socio-éducatifs sont encore très réduites et ponctuelles. L'étude, qui a été réalisée, et dont nous présentons ici les principaux résultats, a pour objectifs centraux: identifier et définir le profil socioprofessionnel des médiateurs socio-éducatifs et caractériser des contextes et des pratiques de médiation socio-éducative. Bien qu'il s'agisse d'une recherche extensive, réalisée au Portugal à niveau national $(\mathrm{N}=225)$, cette étude est de nature exploratoire, à prédominance descriptive. L'analyse des résultats obtenus par l'étude permet de mettre en relief quelques aspects importants qui indiquent l'importance, d'une part, de la continuité de la recherche dans ce secteur et, d'autre part, de l'investissement dans ce domaine d'intervention. Les principales caractéristiques sociodémographiques et professionnelles des médiateurs socio-éducatifs, la diversité de contextes, de types d'intervention et de formation et les aspects relatifs à la perception de l'auto-estime individuelle et de l'appartenance au groupe y sont en évidence.

Mots-clé

Médiation; Médiateurs; Espaces socio-éducatifs; Identité professionnelle

Recebido em Outubro/2009

Aceite para publicação em Agosto/2010

Toda a correspondência relativa a este artigo deve ser enviada para: Ana Maria Costa e Silva, Instituto de Educação, Universidade do Minho, Campus de Gualtar, 4710-057 Braga, Portugal. 


\section{Anexo 1}

\section{ESCALA DE AUTO-ESTIMA COLECTIVA (EAC) \\ Tersào para investigaçăo- \\ (Traduçāo e adaptaçăo de L.uhtanen \& Crocker, 1992) \\ Instituto de Educacão e Psicologia - Universidade do Minho}

Idade: ${ }_{\text {Profissa actual: }}$ Sexo: $\mathrm{M} \_/ \mathrm{F} \_$Data de preenchimento

Instruçōes: Todos nós pertencemos a diferentes grupos ou categorias sociais ao longo da nossa vida. Gostariamos que tivesse em conta a sua pertença ao grupo de profissionais de mediaçăo nas respostas a este questionário. Não existem repostas certas ou erradas. apenas estamos interessados na honestidade das suas reaç̧óes e opiniōes.

Por favor, leia atentamente cada afirmaçăo e responda usando a escala de resposta de 1 a 7. Assim, por exemplo, se concordar totalmente com o que é dito numa afirmaçào, assinale com um círculo o número 7 da escala de resposta apresentada à frente; sce, pelo

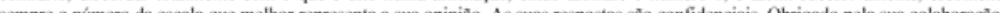

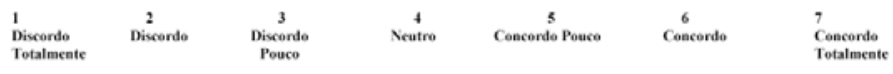

1 - Sou um membro importante do grupo de profissionais de mediação a que pertenço $\quad 123456$,

2 - Por vezes, não gosto de pertencer ao meu grupo de profissionais de mediação $\quad 1234567$

3 - Em geral, o meu grupo de profissionais de mediação é visto de forma positiva 123456 .

4 - Em geral, ser mediador tem pouco a ver com a forma como me sinto em relação a mim próprio/a

1234567

5 - Sinto que não tenho muito a oferecer a este grupo

1234567

6 - Em geral, sinto-me contente por ser membro deste grupo

1234567

7-A maior parte das pessoas considera o meu grupo de profissionais de mediação, em média, menos eficaz do que outros grupos

1234567

8 - O grupo de profissionais de mediação ao qual pertenço é um reflexo importante daquilo que eu sou

$123+367$

9 - Sou um participante activo das actividades deste grupo

1234567

10 - Em geral, sinto que o meu grupo de profissionais de mediaçào é pouco importante

1234567

11 - Em geral, os outros respeitam-me enquanto mediador

1234567

12 - Sinto frequentemente que ser mediador não é importante para o tipo de pessoa que acho que sou

1234567

13 - Sinto frequentemente que sou um membro inútil para este grupo de pertença $\quad 123456$,

14 - Sinto-me bem em relação a este grupo de pertença

$123+567$

15 - Em geral, os outros consideram que o meu grupo de profissionais de medią̧ão não tem valor

1234567

16 - Em geral, pertencer ao meu grupo de mediadores é uma parte importante da minha auto-imagem

1234567 


\title{
Anexo 1
}

Inquérito por Questionário

OP Projecto Colectivo CIEd/UM: PC01-LI-07
Ana Maria Silva, Ana Paula Caetano, Isabel Freire, Maria Alfredo Moreira \& Teresa Freire

\begin{abstract}
Este questionário destina-se a recolher um conjunto de informações junto de Mediadores/as que estão a Este questionário destina-se a recolher um conjunto de informaçōes junto de
exercer funções no dominio da Mediação Escolar, Comunitária e Intercultural.

exercer funções no domínio da Mediação Escolar, Comunitária e Intercultural.
Procura-se, através de um conjunto de questōes, identificar e definir o Perfil Socioprofissional dos/as

Mediadores/as Sócio-Educativos/as.
\end{abstract}

A sua participação é muito importante. Agradecemos, desde já, a sua colaboração.

A. Dados de Identificação

A1.Idade:

A2.Género: Masculino $\square \quad$ Feminino $\square$

A3.Estado civil: Solteiro/a $\square \quad$ Casado/a $\square \quad$ Divorciado/a $\square \quad$ Viưvo/a $\square$

A4.Local de residência:

Localidade _ Concelho __ Distrito

A5.Local de trabalhe:

Localidade Concelho Distrito

\section{B. Dados de caracterização socioprofissional}

B1.Contexto de trabalho actual:

Instituiçằ

Projecto: Identificação

Inicio

Fim

B2.Função que desempenha:

Coordenação $\square \quad$ Mediador/a especializado/a $\square$

Outra $\square$ qual?

Desde

B3. Modo de acesso ao actual trabalho/emprego:

Por concurso $\square \quad$ Por convite/nomeação $\square \quad$ Outro $\square$ Qual?

B4. Situaçăo profissional:

Com vínculo definitivo: $\operatorname{Sim} \square$ Não $\square$; Se sim, há quanto tempo? anos

Com contrato: $\operatorname{Sim} \square$ Năo $\square$; Se sim, com a duraçăo de__ anos; Final do contrato

Outra situaçåo $\square \quad$ Qual? 
Inquérito por Questionário

OP Projecto Colectivo CIEd/UM: PC01-LI-07
Ana Maria Silva, Ana Paula Caetano, Isabel Freire, Maria Alfredo Moreira \& Teresa Freire

Em dedicação exclusiva: $\operatorname{Sim} \square \quad$ Não $\square$

B5. Quais as razões que o/a levaram a trabalhar no âmbito da Mediação Sócio-educativa no contexto do seu trabalho actual?

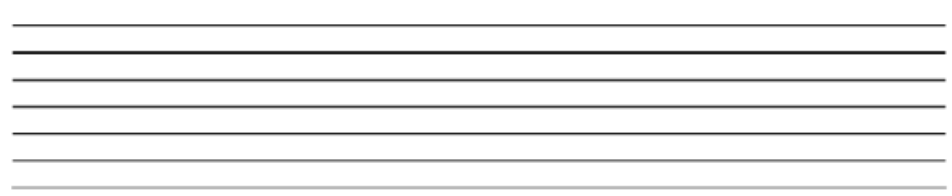

B6. Em que contexto institucional e/ou social exerce a Mediação?

Escolar

Associativo

Municipal _

Outro(s):

B7. Qual a população-alvo da sua intervenção enquanto Mediador/a?

B8. Que tipo(s) de mediação faz junto dessa população?

Conflitos _

Intercultural

Comunitário _

Outro(s):

B9. Que tipo de intervenção faz junto dessa populaçăo?

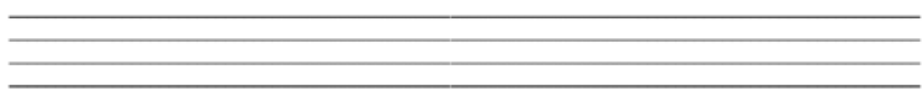

B10. Qual a modalidade da sua intervenção junto dessa população?

Individualmente $\square \quad$ Em equipa $\square$ Se respondeu em equipa, qual a composição da equipa de trabalho? 
Inquérito por Questionário

Projecto Colectivo CIEd/UM: PC01-LI-07
Ana Maria Silva, Ana Paula Caetano, Isabel Freire, Maria Alfredo Moreira \& Teresa Freire

C. Percurso de Formação

\begin{tabular}{|c|c|c|c|}
\hline \multicolumn{4}{|c|}{ Académicas } \\
\hline $\begin{array}{l}\text { Habilitaç̧̃es } \\
\text { Académicas }\end{array}$ & Designaç̧ăo & Instituição & Ano de Conclusão \\
\hline $9^{2}$ ano & $\ldots$ & & \\
\hline $10^{\circ}$ ano & $\ldots$ & & \\
\hline $11^{2}$ ano & $\ldots$ & & \\
\hline 129 ano & $\ldots$ & & \\
\hline \multicolumn{4}{|l|}{ Curso Médio } \\
\hline \multicolumn{4}{|l|}{ Curso Superior } \\
\hline \multicolumn{4}{|l|}{ Pós-graduaç̃̃o } \\
\hline \multicolumn{4}{|l|}{ Mestrado } \\
\hline Doutoramento & & & \\
\hline
\end{tabular}

C2. Formação profissionalizante, habilitadora para o exercício da mediação

C2. Formação profissionalizante, habilitadora para o exercício da mediação
\begin{tabular}{|c|c|c|c|c|}
\hline Designaçăo & Instituição & Duração & Estágio & Ano de Conclusão \\
\hline & & & & \\
\hline & & & & \\
\hline & & & & \\
\hline & & & & \\
\hline
\end{tabular}

C3. Outra(s) Formação(ões) realizada(s) que considere relevante(s):

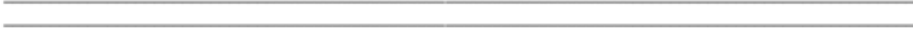

C4. Que perspectivas/expectativas tem para formação futura?

Da lista que se apresenta em seguida indique a(s) situação(ões) que corresponde(m) ao seu caso. Pode indicar mais que

uma situaç̧o,o, por ordem de preferência. (1- maior preferência; 5 - menor preferência).

$\square$ completar a formaçăo académica básica

$\square$ Frequentar cursos de curta duração para formação especializada

$\square$ Frequentar acções de formação especializada na área da mediação

$\square$ Frequentar formação pós-graduada especializada. Em que área(s)?

$\square$ Outra situação. Qual?

C5. Sobre que áreas de actuação dos/as mediadores/as sócio-educativos gostaria de receber formação? 
150 Ana Maria Costa e Silva et al.

\section{Inquérito por Questionário}

Projecto Colectivo CIEd/UM: PC01-LI-07

Ana Maria Silva, Ana Paula Caetano, Isabel Freire, Maria Alfredo Moreira \& Teresa Freire

\section{Perfil Profissional}

D1. Competências do/a mediador/a

Dos itens abaixo listados, assinale o grau de importância que atribui a cada um no exercício das suas funções enquanto mediador/a, utilizando a escala.

\section{\begin{tabular}{|l|l|l|l|l|}
\hline 1-Sem opinis̃o & 2-Nada importante & 3-Pouco importante & 4-Importante & 5-Muito importante \\
\hline
\end{tabular}}

\begin{tabular}{|c|c|c|c|c|c|c|}
\hline & & & & & & \\
\hline a & Conhecer os códigos linguisticos da populaçăo & 1 & 2 & 3 & 4 & 5 \\
\hline b & Estar disponivel para os outros & 1 & 2 & 3 & 4 & 5 \\
\hline c & Ser corajoso & 1 & 2 & 3 & 4 & 5 \\
\hline d & Ser responsável & 1 & 2 & 3 & 4 & 5 \\
\hline e & Ser flexivel & 1 & 2 & 3 & 4 & 5 \\
\hline$f$ & Ser capaz de ouvir os outros & 1 & 2 & 3 & 4 & 5 \\
\hline $\mathrm{g}$ & Ser prudente & 1 & 2 & 3 & 4 & 5 \\
\hline $\mathrm{h}$ & Ser capaz de identificar problemas & 1 & 2 & 3 & 4 & 5 \\
\hline $\mathrm{i}$ & Conhecer traços culturais dominantes da população com quem trabalha & 1 & 2 & 3 & 4 & 5 \\
\hline j & Ser assertivo & 1 & 2 & 3 & 4 & 5 \\
\hline $\mathrm{k}$ & Ser auto-confiante & 1 & 2 & 3 & 4 & 5 \\
\hline 1 & Ser empático na relação com os outros & 1 & 2 & 3 & 4 & 5 \\
\hline $\mathrm{m}$ & Ter sentido de humor & 1 & 2 & 3 & 4 & 5 \\
\hline$n$ & Ser imparcial & 1 & 2 & 3 & 4 & 5 \\
\hline o & Acreditar no outro & 1 & 2 & 3 & 4 & 5 \\
\hline $\mathrm{p}$ & Promover o diálogo entre pessoas ou grupos & 1 & 2 & 3 & 4 & 5 \\
\hline$q$ & Ter auto-controlo & 1 & 2 & 3 & 4 & 5 \\
\hline $\mathrm{r}$ & Respeitar o outro & 1 & 2 & 3 & 4 & 5 \\
\hline s & Ser paciente & 1 & 2 & 3 & 4 & 5 \\
\hline $\mathrm{t}$ & Ser capaz de gerir a comunicaçăo interpessoal & 1 & 2 & 3 & 4 & 5 \\
\hline u & Ser tolerante ao stress & 1 & 2 & 3 & 4 & 5 \\
\hline $\mathrm{v}$ & Ser criativo & 1 & 2 & 3 & 4 & 5 \\
\hline w & Ser realista & 1 & 2 & 3 & 4 & 5 \\
\hline$x$ & Ser resistente às adversidades & 1 & 2 & 3 & 4 & 5 \\
\hline $\mathrm{y}$ & Ser optimista & 1 & 2 & 3 & 4 & 5 \\
\hline 2 & Interessar-se pelo bem dos outros & 1 & 2 & 3 & 4 & 5 \\
\hline $\mathrm{Aa}$ & Ser perseverante & 1 & 2 & 3 & 4 & $\underline{5}$ \\
\hline$\overline{A b}$ & Ser respeitado na comunidade/grupo & 1 & 2 & 3 & 4 & 5 \\
\hline $\mathrm{AC}$ & Tentar resolver os problemas o mais depressa possivel & 1 & 2 & 3 & 4 & 5 \\
\hline $\mathrm{Ad}$ & Ser capaz de gerir a agressividade dos outros & 1 & 2 & 3 & 4 & 5 \\
\hline $\mathrm{Ae}$ & Ser simpático & 1 & 2 & 3 & 4 & 5 \\
\hline Af & Ser falador & 1 & 2 & 3 & 4 & $\frac{5}{5}$ \\
\hline $\mathrm{Ag}_{\mathrm{B}}$ & Saber resolver os conflitos dos outros & 1 & 2 & 3 & 4 & 5 \\
\hline Ah & Ser bom observador/estar atento ao que o rodeia & 1 & 2 & 3 & 4 & 5 \\
\hline Ai & Estar motivado para aquilo que faz & 1 & 2 & 3 & 4 & 5 \\
\hline Aj & Ser muito activo & 1 & 2 & 3 & 4 & 5 \\
\hline
\end{tabular}


Inquérito por Questionário

P Projecto Colectivo CIEd/UM: PC01-LI-07
Ana Maria Silva, Ana Paula Caetano, Isabel Freire, Maria Alfredo Moreira \& Teresa Freite

D2. Que conhecimentos/saberes considera que os/as mediadores/as sócio-educativos devem possuir?

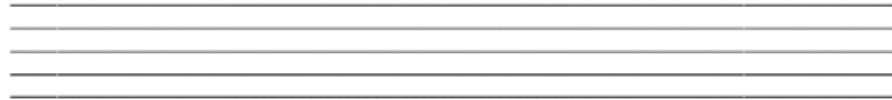

D3. Refira três dos principios fundamentais em que baseia a sua actuação como mediador/a sócioeducativo/a.

E. Trajectória Profissional

E1. Por favor, descreva a sua trajectória profissional. No quadro que apresentamos de seguida, liste os empregos que teve, os cargos e as funçōes desempenhadas e os anos em que desempenhou essas funçōes (enuncie as funçōes que desempenhou, nomeadamente se desempenhou funçōes de mediação e de que tipo).

\begin{tabular}{|l|l|l|l|}
\hline \multicolumn{1}{|c|}{ Empregos - Instituição } & Cargo(s) & Funçōes & Ano \\
\hline $1^{2}$ & & & \\
\hline $2^{2}$ & & & \\
\hline 39 & & & \\
\hline 49 & & & \\
\hline 59 & & & \\
\hline 69 & & & \\
\hline 79 & & & \\
\hline$\ldots$. & & & \\
\hline Actual & & & \\
\hline
\end{tabular}

E2. Gostaria de continuar a exercer funções de Mediação, neste ou noutro contexto socioprofissional? Sim__ Năo _

Porquê?

$\overline{\overline{ }} \overline{\overline{ }}$

E3. Quais as suas expectativas profissionais para o futuro? 